\title{
A role for bone morphogenetic proteins in the induction of cardiac myogenesis
}

\author{
Thomas M. Schultheiss, ${ }^{1}$ John B.E. Burch, ${ }^{2}$ and Andrew B. Lassar ${ }^{1,3}$ \\ ${ }^{1}$ Department of Biological Chemistry and Molecular Pharmacology, Harvard Medical School, Boston, Massachusetts 02115 \\ USA; ${ }^{2}$ Fox Chase Cancer Center, Philadelphia, Pennsylvania 19111 USA
}

\begin{abstract}
Little is known about the molecular mechanisms that govern heart specification in vertebrates. Here we demonstrate that bone morphogenetic protein (BMP) signaling plays a central role in the induction of cardiac myogenesis in the chick embryo. At the time when chick precardiac cells become committed to the cardiac muscle lineage, they are in contact with tissues expressing BMP-2, BMP-4, and BMP-7. Application of BMP-2-soaked beads in vivo elicits ectopic expression of the cardiac transcription factors CNkx-2.5 and GATA-4. Furthermore, administration of soluble BMP-2 or BMP-4 to explant cultures induces full cardiac differentiation in stage 5 to 7 anterior medial mesoderm, a tissue that is normally not cardiogenic. The competence to undergo cardiogenesis in response to BMPs is restricted to mesoderm located in the anterior regions of gastrula- to neurula-stage embryos. The secreted protein noggin, which binds to BMPs and antagonizes BMP activity, completely inhibits differentiation of the precardiac mesoderm, indicating that BMP activity is required for myocardial differentiation in this tissue. Together, these data imply that a cardiogenic field exists in the anterior mesoderm and that localized expression of BMPs selects which cells within this field enter the cardiac myocyte lineage.
\end{abstract}

[Key Words: Heart; induction; bone morphogenetic proteins; Nkx-2.5; noggin]

Received August 22, 1996; revised version accepted December 24, 1996.

The vertebrate heart develops from paired mesodermal primordia that migrate to the anterior ventral midline, where they fuse and undergo terminal differentiation (Rosenquist and DeHaan 1966; Han et al. 1992; GarciaMartinez and Schoenwolf 1993). In both chick and Xenopus embryos, the cardiac primordia become specified during gastrulation (Jacobson and Sater 1988; Sater and Jacobson 1989; Gonzalez-Sanchez and Bader 1990; Holtzer et al. 1990; Antin et al. 1994; Nascone and Mercola 1995). Embryological studies have suggested roles for both anterior endoderm (Jacobson 1960; Jacobson and Sater 1988; Nascone and Mercola 1995; Schultheiss et al. 1995) and the organizer region (Sater and Jacobson 1990; Nascone and Mercola 1995) in vertebrate cardiac lineage specification, but the molecular mechanisms through which these inducing tissues act are currently unknown.

In Drosophila, the heart is derived from the dorsalmost region of the mesoderm (Bate 1993). The homeobox-containing gene tinman is expressed in the Drosophila heart and is required for cardiogenesis (Bodmer et al. 1990; Bodmer 1993). Recent studies in the fly have determined that cardiac expression of tinman is regulated in part by the transforming growth factor- $\beta$ (TGF- $\beta$ ) family member decapentaplegic ( $d p p$ ) (Frasch 1995). $d p p$ is expressed dorsally in the ectoderm overlying the car-

${ }^{3}$ Corresponding author.

E-MAIL lassarab@warren.med.harvard.edu; FAX (617) 738-0516. diac mesoderm, and ectopic expression of $d p p$ in more ventral regions of the embryo induces expansion of tinman expression ventrally, although it does not induce ectopic expression of later cardiac markers (Frasch 1995).

In vertebrates, we (Schultheiss et al. 1995) and others (Komuro and Izumo 1993; Lints et al. 1993; Tonissen et al. 1994; Lee et al. 1996) have found that the tinman homolog Nkx-2.5 is expressed in the precardiac mesoderm prior to heart formation and is one of the earliest markers of the cardiac lineage. Because dorsal-ventral patterning mechanisms have been found to be highly conserved from Drosophila to vertebrates (for review, see DeRobertis and Sasai 1996), we have studied whether TGF- $\beta$ family members might similarly regulate expression of Nkx-2.5 and other cardiac genes in the chick. In this work we document that bone morphogenetic protein-2 (BMP-2) and BMP-4 and BMP-7 are expressed in the endoderm and ectoderm, respectively, which lie adjacent to the Nkx-2.5-positive precardiac mesoderm. Implantation of BMP-2-laden beads can expand Nkx-2.5 expression specifically in the anterior paraxial mesoderm, and culture of this tissue in vitro with either BMP-2 or BMP-4 induces robust cardiac myocyte differentiation. Furthermore, incubation of precardiac mesoderm with noggin, an antagonist of BMP signaling (Zimmerman et al. 1996), inhibits cardiac myogenesis. Together, these findings indicate that BMP signaling is a necessary component of cardiac myocyte specification in vertebrates. 


\section{Results}

BMPs are expressed in tissues adjacent to the precardiac mesoderm

Degenerate PCR (see Materials and Methods) was employed to amplify TGF- $\beta$ family members present in cDNA synthesized from stage 5 (Hamburger and Hamilton 1951) anterior endoderm, a tissue shown previously to have cardiac-inducing properties (Schultheiss et al. 1995). Several TGF- $\beta$ family members were identified using this strategy, including BMP-2 and BMP-7. We also investigated the potential role of BMP-4 in heart formation even though it was not detected in this screen, because BMP-4 is both highly related to and functionally interchangeable with BMP-2 (Kingsley 1994; Massague et al. 1994; Wall and Hogan 1994; Hemmati-Brivanlou and Thomsen 1995; Hogan 1996).

The expression patterns of chick BMP-2, BMP-4, and BMP-7 were monitored by whole-mount in situ hybridization and compared with the expression patterns of chick Nkx-2.5 (CNkx-2.5) and GATA-4, a zinc finger cardiac transcription factor expressed in the heart and implicated in the expression of cardiac genes (Arceci et al. 1993; Grepin et al. 1994; Ip et al. 1994; Laverriere et al. 1994; Molkentin et al. 1994). Precardiac cells emerge from the primitive streak at stage 3 and migrate anterolaterally through the mesoderm (Rosenquist and DeHaan 1966; Garcia-Martinez and Schoenwolf 1993). Tissue culture experiments have found that mesodermal cells first become specified to the cardiac lineage beginning at stage $4^{+}$to 5 (Gonzalez-Sanchez and Bader 1990; Holtzer et al. 1990; Antin et al. 1994) and that the cardiac myocyte population continues to expand in the embryo at least through stage 8 /Gonzalez-Sanchez and Bader 1990). At stage 4, BMP-4 is expressed widely in the embryo, except for an area around Hensen's node, and is exclusively ectodermal (Fig. 1A,C). As seen in Figure 1C, the lateral region of stage 4 embryos that has been found to contain precardiac mesoderm (Rosenquist and DeHaan 1966; Gonzalez-Sanchez and Bader 1990; Antin et al. 1994) is overlain by BMP-4-expressing ectoderm. Thus, from the time cells are first becoming specified to the myocardial lineage, precardiac mesoderm is in contact with BMP-4-expressing ectoderm. While BMP-2 is also expressed broadly in the stage 4 embryo (in the periphery of the area pellucida and in the posterior half of the primitive streak; Fig. $1 \mathrm{~B}$ ), sectioning indicates that at this stage the precardiac mesoderm is not yet in contact with BMP-2-expressing tissues (Fig. 1D,E).

CNkx-2.5 is first expressed at stage 5-6 in the anterior half of the embryo in a crescent-shaped pattern that overlaps the cardiac fate map (Fig. 2A, $\mathrm{K}_{\text {; }}$ see also Rosenquist and DeHaan 1966; Schultheiss et al. 1995). At this stage, GATA-4 is expressed around the periphery of the embryo, both anteriorly, where it overlaps the cardiac fate map, and at the posterior end (Fig. 2B). As development proceeds, the anterior expression domains of CNkx-2.5 and GATA-4 continue to be associated with the developing heart (Schultheiss et al. 1995; data not shown). At stage 6, BMP-2 (Fig. 2C), BMP-4 (Fig. 2D), and BMP-7
(Fig. 2E) are expressed in the periphery of the embryo and excluded from the central regions. Anteriorly, the BMP expression patterns overlap the domains of both CNkx2.5 and GATA-4 expression. Sections through the anterior regions of whole-mount preparations demonstrated that whereas CNkx-2.5 and GATA-4 are expressed in mesoderm (Fig. 2F,G), BMP-2 is expressed in the adjacent endoderm (Fig. 2H), and BMP-4 and BMP-7 in the ectoderm (Fig. 2I,J; BMP-7 is also expressed at low levels in the endoderm near the anterior intestinal portal; data not shown).

Exogenous BMP-2 induces ectopic expression of early cardiac markers in vivo

The overlap between the expression domains of BMP-2, BMP-4, and BMP-7 and the cardiac transcription factors CNkx-2.5 and GATA-4 in the anterior region of the embryo raised the possibility that BMPs may play a role in regulating cardiac gene expression. To address this issue, heparin-acrylamide beads soaked in recombinant BMP-2 were positioned medial to the heart-forming region in stage 3 to 5 chick embryos (Fig. 3A). The embryos were allowed to develop until stages 8-11 (Fig. 3B) and were subsequently processed for whole-mount in situ hybridization. This procedure revealed that implantation of BMP-2 beads, but not control beads, induced strong ectopic expression of $\mathrm{CNkx}-2.5$ in cells immediately surrounding the bead (Fig. $3 \mathrm{C}-\mathrm{E}$ ) in a domain medial to the normal region of CNkx-2.5 expression. GATA-4 was also induced (Fig. 3F,G), but significantly less robustly than CNkx-2.5, whereas ectopic ventricular myosin heavy chain (vMHC), a marker of terminal cardiac differentiation (Bisaha and Bader 1991), was not induced by implantation of BMP-2 beads into this anterior medial position (data not shown).

Competence to express CNkx-2.5 in response to BMP-2 is limited to the anterior mesoderm

Interestingly, not all areas of the embryo were competent to express CNkx-2.5 in response to BMP-2 beads. Ectopic CNkx-2.5 was induced only if the BMP-2 beads were implanted into the anterior medial region of the embryo. BMP- 2 beads that were positioned in the posterior region of stage 3 to 5 embryos did not induce ectopic CNkx-2.5 expression (Fig. 4B-D). Although paraxial mesodermal cells posterior to the heart-forming region did not initiate CNkx-2.5 expression in response to exogenous BMP-2, somite formation was disrupted in this region (Fig. 4A). Thus, posteriorly located paraxial mesoderm displayed a biological response to BMP-2 but failed to activate $\mathrm{CNkx}-2.5$ expression. A restriction in the competence of mesoderm to express ectopic CNkx2.5 in response to BMP-2 is consistent with the fact that while BMP- 2 is expressed in both the anterior and posterior regions of the embryo (Fig. 2C), CNkx-2.5 is expressed only anteriorly (Fig. 2A). Thus, it appears that a field of cells exists in the anterior embryo that is competent to express CNkx-2.5, and that BMP-2 may act to 

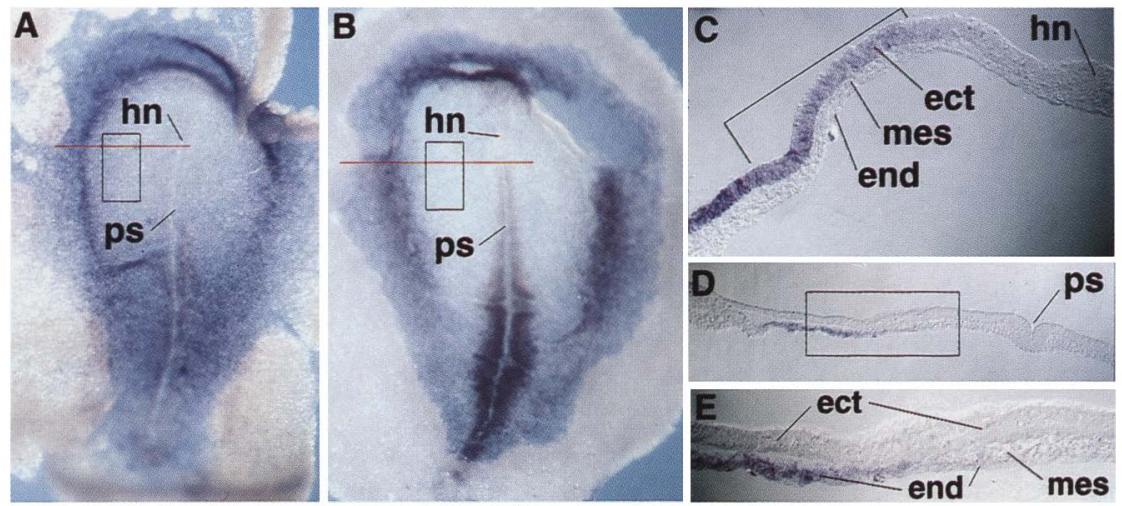

Figure 1. Expression of BMP-2 and BMP-4 at early stages of cardiac specification. Whole-mount in situ hybridization of stage 4 embryos for BMP-4 $(A, C)$ and BMP-2 $(B, D, E)$. At stage $4, \mathrm{BMP}-4$ is expressed broadly in the ectoderm, including the region overlying the precardiac mesoderm $(A, C)$. BMP-2 is expressed at the periphery of the embryo and in the posterior primitive streak $(B)$. At the level of the anterior primitive streak, BMP-2 is expressed in the lateral endoderm $(D)$; at this stage, mesoderm has not yet migrated to contact the BMP-2-expressing endoderm $(E$, which is a higher magnification of the boxed area in $D$ ). (ect) Ectoderm; (end) endoderm; (hn) Hensen's node; (mes) mesoderm; (ps) primitive streak. The red lines in $A$ and $B$ indicate the approximate levels of the sections in $C$ and $D$. The boxed areas in $A$ and $B$ and the bracketed area in $C$ indicate the approximate region of the precardiac mesoderm (Rosenquist 1966). The hole in the upper right of the embryo in $B$ is an artifact.

define which portion of that field expresses CNkx-2.5 and goes on to differentiate into heart.

\section{Soluble BMP-2 induces full ectopic cardiac myogenic differentiation in explant culture}

There could be several reasons why BMP-2 beads induced robust ectopic expression of CNkx-2.5 but only weak expression of GATA-4 and no expression of vMHC in the anterior medial mesoderm: GATA-4 and vMHC expression may require different or additional inducing molecules; negative signals from surrounding tissues may inhibit the expression of a subset of cardiac genes including GATA-4 and vMHC; or the anterior medial mesoderm may not be competent to undergo full cardiac differentiation. To distinguish between these possibilities, we assayed the induction of cardiac differentiation markers in explants of anterior medial mesoderm cul-

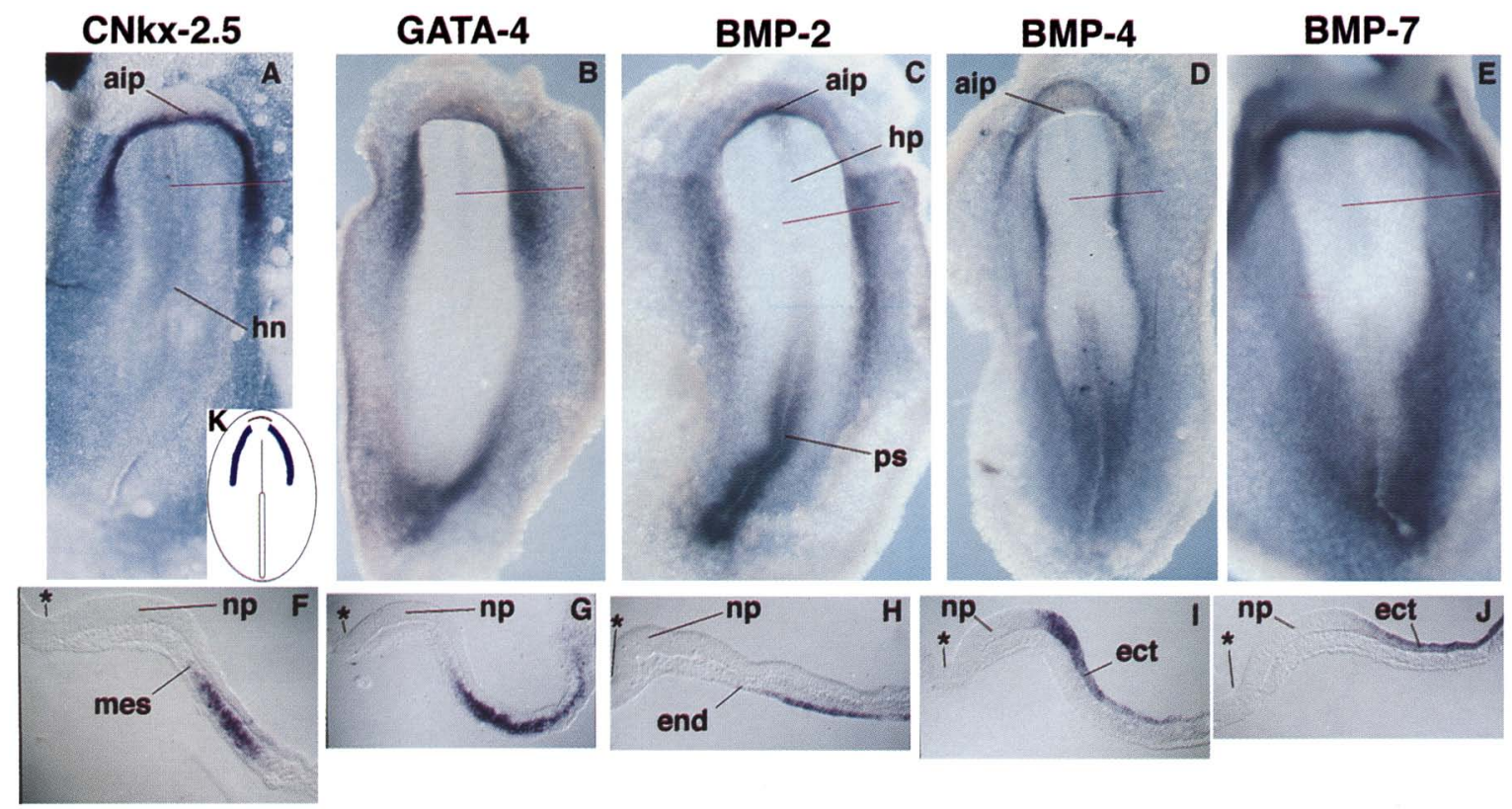

Figure 2. Expression of CNkx-2.5 (A,F), GATA-4 (B,G), BMP-2 $(C, H)$, BMP-4 $(D, I)$ and BMP-7 (E, $/)$ genes as assessed by whole-mount in situ hybridization in stage 6 chick embryos. Note that all five genes are expressed in the anterior/lateral region of the embryo, overlapping the precardiac region [in $K$, the precardiac region is outlined in blue (Rosenquist and DeHaan 1966)]. GATA-4 and the BMPs are also expressed in more posterior regions. $(F-I)$ Sections taken at the approximate levels indicated by the red lines in $A-E$. Within the anterior lateral region, CNkx-2.5 and GATA-4 are expressed in the mesoderm $(F, G), \mathrm{BMP}-2$ in the endoderm $(H)$, and BMP-4 $(I)$ and BMP-7 $(J)$ in the ectoderm. (aip) Anterior intestinal portal; $(\mathrm{np})$ neural plate. Otherwise, as in Fig. 1 . Asterisks $\left({ }^{\star}\right)$ indicate the neural groove. 
Figure 3. BMP-2 induces CNkx-2.5 and GATA-4. Heparin-acrylamide beads soaked in BMP-2 $(b)$ or control beads $(c)$ were placed in stage 3 to 5 embryos $(A)$, and the embryos were incubated until stage $8-11(B)$, at which time whole-mount in situ hybridization was performed for CNkx-2.5 $(C-E)$ or GATA-4 $(F, G)$. In $C$, which is the same embryo as $A$ and $B$, the BMP-2 bead induced a thin rim of ectopic CNkx-2.5 expression; $(E)$ a section from this embryo; $(D)$ another embryo, in which the CNkx-2.5 induction is stronger. Ectopic GATA-4 was also induced by BMP-2 $(F, G)$ but to a weaker degree than $\mathrm{CNkx}$ 2.5; note that the beads in this embryo are at approximately the same axial level as the beads in $C$ and $E$. (n) Notochord; (np) neural plate. Shown are representative results from 99 embryos in 12 separate experiments $(\mathrm{CNkx}-2.5 \mid$, and 16 embryos in 5 separate experiments (GATA-4).
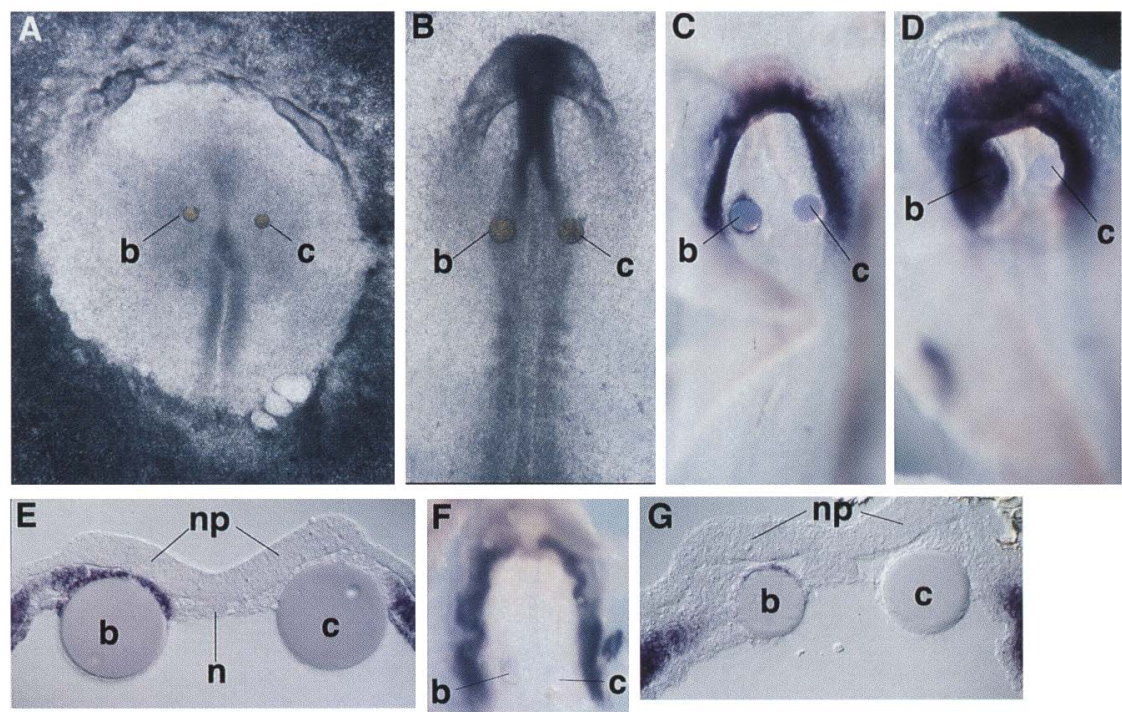

tured in the presence of various BMPs, various surrounding tissues, and other potential cardiac inducers. It was important that this assay employ tissues that would not normally contribute to the heart. We therefore used anterior medial tissues from within the borders of the neural plate (AM in Fig. 5A), because expression of CNkx-2.5 and GATA-4, which are early cardiac markers, always occurs lateral to the borders of the neural plate (Fig. 2; see also Schultheiss et al. 1995). This anterior medial mesoderm is normally fated to give rise to head mesoderm (Rosenquist 1966). These in vitro experiments also served another purpose. Much cell movement occurs in the embryo between the time of bead placement and the activation of cardiac-specific gene expression. It is therefore possible that the expression of cardiac markers around the BMP-2 beads (Fig. 3) was not attributable to induced gene expression but, rather, to migration of cardiac progenitors from the precardiac mesoderm. The following experiments also helped to evaluate this possibil- ity, by investigating whether BMP administration could activate cardiogenesis in anterior medial tissues that had been cultured in isolation from the precardiac mesoderm.

Explants of stage 6 anterior lateral (AL in Fig. 5) mesoendoderm (which lies in the cardiac fate map) initiated the expression of both early (CNkx-2.5 and GATA-4) and late (vMHC) cardiac markers and differentiated into beating heart after $48 \mathrm{hr}$ in culture (Fig. 5A, lane 1). Similarly incubated explant cultures prepared from anterior medial mesoendoderm expressed only trace levels of CNkx-2.5 and undetectable amounts of GATA-4 and vMHC, and failed to beat (Fig. 5A, lane 6). However, when the anterior medial mesoendoderm was cultured in the presence of $200 \mathrm{ng} / \mathrm{ml}$ of recombinant BMP-2 it gave rise to beating tissue that robustly expressed all three cardiac markers (Fig. 5A, lane 5), demonstrating that BMP-2 can induce a full cardiogenic response from anterior medial mesoderm. CNkx-2.5 and GATA-4 were
Figure 4. Competence to express CNkx2.5 in response to ectopic BMP-2 is limited to anterior tissues. BMP-2 beads located in the somite region did not induce ectopic CNkx-2.5 expression $(A-C)$. Note, however, that the posterior BMP-2 bead interfered with somite development $(A)$. A schematic view of a stage 8 embryo is given in $D$, with purple designating the normal domain of CNkx-2.5 expression and yellow denoting the region that is competent to express ectopic CNkx-2.5 in response to BMP-2 administration. The map was derived from 99 embryos in 12 separate experiments. (som) Somites. Otherwise, as in Fig. 2.
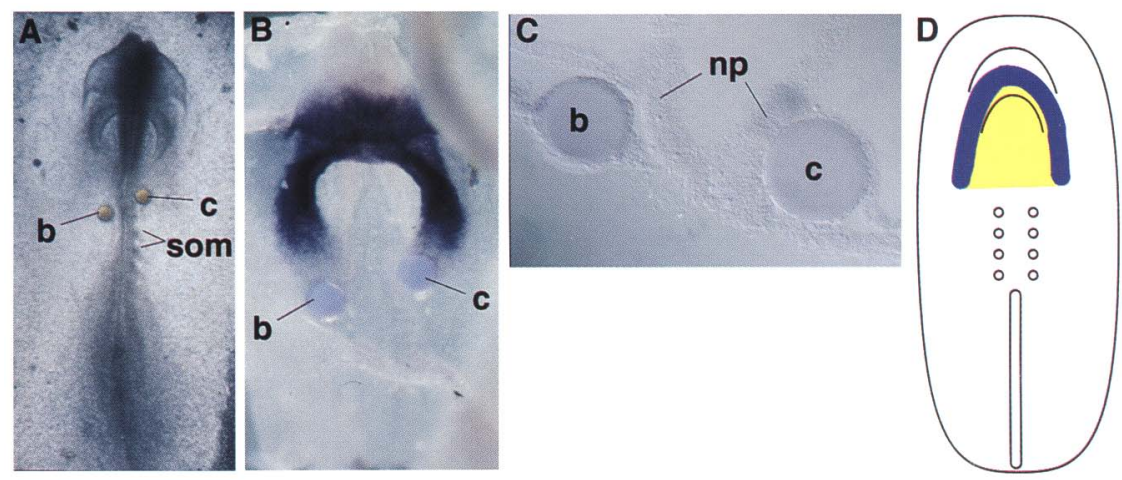
A

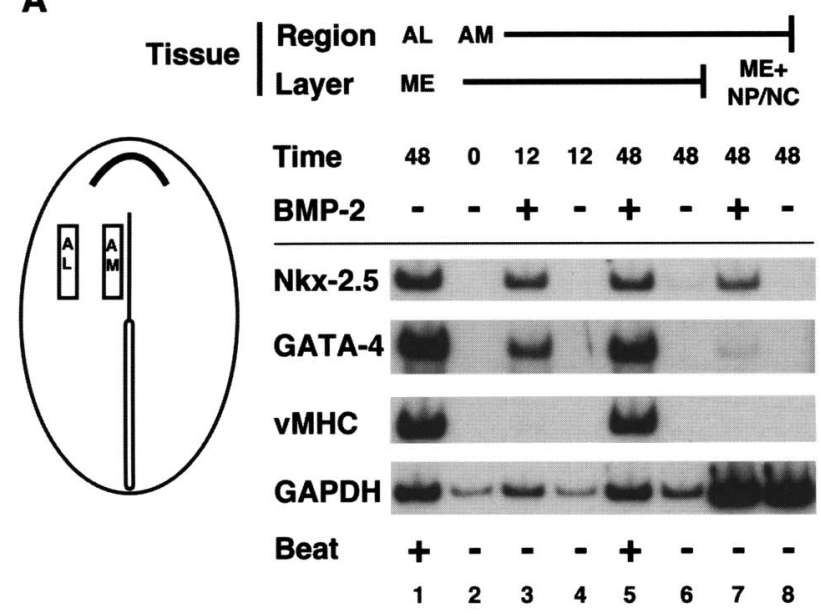

B

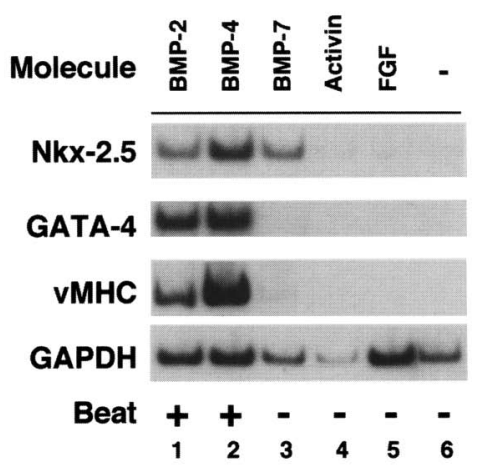

Figure 5. (A) Induction of cardiogenesis by BMP-2 in explant culture. Tissues were dissected from stage 6 chick embryos as indicated and cultured in either the presence or the absence of $200 \mathrm{ng} / \mathrm{ml}$ of BMP-2. After the indicated length of time, explants were evaluated for the presence of beating, RNA was harvested, and transcript levels of CNkx-2.5, GATA-4, vMHC, and glyceraldehyde-3-phosphate dehydrogenase (GAPDH) were monitored by RT-PCR analysis. (B) Cardiac-inducing properties of selected growth factors. Anterior medial mesoendoderm from stage 6 embryos was incubated in the presence of $200 \mathrm{ng} / \mathrm{ml}$ of BMP-2 (lane 1), $200 \mathrm{ng} / \mathrm{ml}$ of BMP-4 (lane 2), $200 \mathrm{ng} / \mathrm{ml}$ of BMP-7 (lane 3), $100 \mathrm{U} / \mathrm{ml}$ of human activin $\beta A$ (lane 4), 10 $\mathrm{ng} / \mathrm{ml}$ of bFGF (lane 5), or no additive (lane 6). After $48 \mathrm{hr}$, explants were evaluated for the presence of beating, RNA was harvested, and transcript levels of CNkx-2.5, GATA-4, vMHC, and GAPDH were monitored by RT-PCR analysis. Each lane is representative of results from at least three separate cultures. (AL) Anterior lateral; (AM) anterior medial (within the borders of the neural plate); (ME) mesoendoderm; (NP/NC) neural plate and notochord.

induced within $12 \mathrm{hr}$ of BMP-2 administration, whereas expression of $\mathrm{vMHC}$ was relatively delayed (Fig. 5A, lanes 3,51 , recapitulating the in vivo temporal expression patterns of these genes (Bisaha and Bader 1991; Schultheiss et al. 1995). Consistent with the inability of BMP2-laden beads to induce CNkx-2.5 expression in the posterior domain of the embryo, BMP-2 administration to explants of posterior medial mesoendoderm failed to in- duce CNkx-2.5 (data not shown). Because of the difficulty of removing the anterior medial endoderm without damaging the anterior medial mesoderm, most of the explant cultures utilized anterior medial mesoendoderm as the respoinding tissue. However, full cardiac differentiation could also be induced in anterior medial mesoderm by BMP-2 administration (data not shown), indicating that BMP-2 was acting directly on the anterior medial mesoderm rather than altering the signaling properties of the anterior medial endoderm. In addition to undergoing cardiogenesis, anterior medial tissues treated with BMP-2 also expressed higher levels of GAPDH (Fig. 5A, lanes 3-6), suggesting that BMP-2 promoted cell proliferation, cell survival, or both.

\section{Axial tissues inhibit the cardiogenic effects of BMP-2}

The full cardiogenic response of anterior medial mesoendoderm to BMP-2 occurred when this tissue was cultured in isolation from the adjacent axial tissues (Fig. 5A, lane 5). In contrast, when this tissue was cultured together with the adjacent neural plate and notochord, BMP-2 administration induced robust expression of CNkx-2.5, but only low levels of GATA-4, no detectable level of vMHC, and this tissue did not beat (Fig. 5A, lane 7). Thus, signals from axial tissues can apparently inhibit induction of the cardiac differentiation program downstream of CNkx-2.5 activation. The repressive influence of the neural tube and notochord on terminal cardiac muscle differentiation may explain why implantation of BMP-2-laden beads into the anterior medial mesoderm in vivo induced CNkx-2.5 strongly, but induced GATA-4 only weakly, and failed to induce vMHC (Fig. 3).

\section{Cardiac-inducing properties of other signaling molecules}

To assess whether signaling molecules other than BMP-2 could induce cardiogenesis in anterior medial mesoendoderm, we examined the effect of culturing this tissue with other TGF- $\beta$ family members or with various signaling molecules that have been suggested previously to play a role in cardiac induction (Logan and Mohun 1993; Sugi and Lough 1995). BMP-4, the TGF- $\beta$ family member that is related most closely to BMP-2 and is expressed in the anterior lateral ectoderm (Figs. 1A,C and Fig. 2D,I), displayed cardiac-inducing activity indistinguishable from BMP-2 (Fig. 5B, lanes 1,2). BMP-7 induced CNkx2.5 to levels similar to those obtained with either BMP-2 or BMP-4 (Fig. 5B, lane 3); unlike those factors, however, BMP-7 failed to induce expression of GATA-4 or vMHC and beating was not observed (Fig. 5B, lane 3). This finding suggests that there may be mechanistic differences underlying the induction of various components of the cardiac differentiation program. Both the TGF- $\beta$ family member activin and basic fibroblast growth factor (bFGF) have been implicated in promoting the terminal differentiation of precardiac mesoderm (Logan and Mohun 1993; Sugi and Lough 1995). However, when employed at 
concentrations known to be physiologically effective, neither displayed any discernible cardiac-inducing effect on anterior medial mesoendoderm (Fig. 5B, lanes 4,5).

\section{Inhibition of BMP signaling with noggin blocks differentiation of the precardiac mesoderm}

The findings described above indicate that BMP signaling is sufficient to induce cardiogenesis in competent regions of the anterior mesoderm. To determine whether BMP signaling is required for cardiac myogenesis, we sought to inhibit endogenous BMP signaling in the precardiac region. Noggin is a secreted protein, first identified in Xenopus, that is capable of inducing neural tissue and dorsalizing mesoderm in either Xenopus embryos or in explanted tissues (Smith and Harland 1992; Smith et al. 1993). Recent work has demonstrated that noggin and BMP-4 display antagonistic activities ( $\mathrm{Re}^{\prime} \mathrm{em}$-Kalma et al. 1995; Zimmerman et al. 1996) and that noggin specifically binds to and inactivates BMP-2, BMP-4 and, to a lesser extent, BMP -7 (Zimmerman et al. 1996). In light of the specific ability of noggin to block BMP signaling, we investigated the effects of this agent on the differentiation of precardiac mesoderm. Stage 4 precardiac mesoendoderm incubated with supernatant conditioned by Chinese hamster ovary ( $\mathrm{CHO}$ ) cells programmed to secrete noggin failed to express the genes $\mathrm{CNkx}-2.5$ and vMHC and did not beat (Fig. 6, lanes 1,3), whereas precardiac mesoendoderm incubated with control supernatant differentiated into beating heart tissue that expressed both CNkx-2.5 and vMHC (Fig. 6, lanes 2,4). Thus, noggin administration to precardiac mesoderm can inhibit cardiac myocyte gene expression, indicating that BMP signaling is required for the differentiation of precardiac mesoendoderm into cardiac tissue.

\section{Discussion}

In this paper we provide several lines of evidence that,
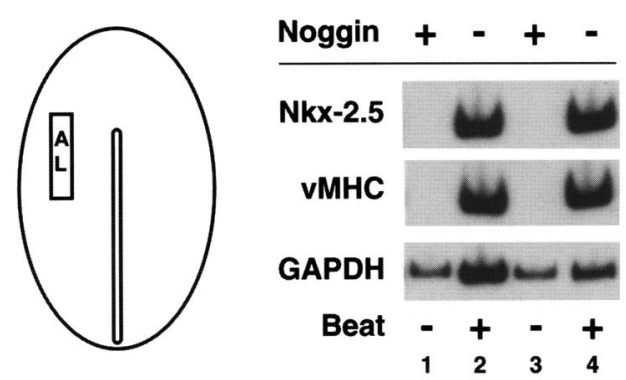

Figure 6. The BMP antagonist noggin inhibits myocardial differentiation. Precardiac mesoendoderm from the anterior lateral region of stage 4 embryos was cultured in medium conditioned by $\mathrm{CHO}$ cells expressing noggin (lanes 1,3 ) or in medium conditioned by control $\mathrm{CHO}$ cells (lanes 2,4). Explants were cultured for $48 \mathrm{hr}$ and RT-PCR was performed for Nkx-2.5, vMHC, and GAPDH. Control explants differentiated into beating heart tissue that expressed both myocardial genes, whereas noggintreated explants failed to express any myocardial markers and did not beat. together, strongly suggest that BMP signaling plays a crucial role in cardiac specification in the chick embryo.

BMPs are expressed at the appropriate time and place to be involved in heart specification

In the avian embryo, cardiac precursors emerge from the primitive streak at stage 3 and migrate anterolaterally through the mesoderm (Rosenquist and DeHaan 1966; Garcia-Martinez and Schoenwolf 1993). Explantation of prospective cardiac mesoderm into tissue culture has indicated that cells become specified to the myocardial lineage beginning at stages $4^{+}-5$ (Gonzalez-Sanchez and Bader 1990; Holtzer et al. 1990; Antin et al. 1994). Recruitment of cells to the cardiac lineage may continue at least through stages 5 and 6 , as when cells from the cardiogenic regions are placed into tissue culture, the proportion of cells that differentiates into cardiac muscle increases between stages 4 and 6 (Gonzalez-Sanchez and Bader 1990). The current data indicate that as early as stage 4 , the precardiac mesoderm is in contact with BMP-4-expressing ectoderm, and that from stage 5 onward it is in contact with BMP-2-expressing endoderm. The BMP expression data are thus consistent with a role for BMP signaling in heart specification.

BMPs can induce ectopic cardiac myogenesis, in combination with a second anterior endodermal factor

Placement of BMP-2 beads in vivo induced ectopic expression of the early cardiac markers $\mathrm{CNkx}-2.5$ and GATA-4 in regions of the embryo that lie medial to their normal domains of expression. Treatment of explanted anterior medial mesoendoderm with either soluble BMP2/BMP-4 (Fig. 5A,B) or with BMP-2 beads (data not shown/ induced full cardiac differentiation in this tissue, including vMHC expression and beating. Therefore, BMP signaling is capable of inducing cardiac differentiation from the anterior medial mesoderm, which is normally fated to give rise to head mesenchyme (Rosenquist 1966).

It should be emphasized, however, that BMP-2/BMP-4 can induce heart formation only in the anterior and not in the posterior mesoderm; BMPs are broadly expressed in posterior regions of the embryo without inducing cardiogenesis in this area. This suggests that a cardiogenic field exists in the anterior mesoderm and that BMP signaling acts to induce cardiac differentiation within a lateral subdomain of that field. In previous work, we have shown that anterior endoderm, unlike BMP-2/BMP-4, can induce cardiogenesis in cells from posterior tissues whose normal fate is to form blood and extraembryonic membranes (Schultheiss et al. 1995). It is therefore likely that the anterior endoderm contains an additional activity (apart from BMP-2) whose effect is to create this cardiogenic field in the overlying anterior mesoderm. Cardiac induction thus appears to require at least two activities. One activity consists of unknown factors in the anterior endoderm that act to create a cardiogenic field in the overlying anterior mesoderm. The second activity-BMP signaling-induces cells in the lateral subdo- 
main of this field to differentiate into heart. The order in which these signals are received may not be important. Here we have shown that BMP signaling can induce heart from competent cells in the anterior central mesoderm, whereas we have found previously that the posterior primitive streak, which expresses BMP-2 at high levels, will give rise to heart when exposed to anterior endoderm (Schultheiss et al. 1995). A model of the proposed two-step cardiac induction process is presented in Figure 7.

The current studies, taken together with explant studies indicating that precardiac mesoderm removed from the embryo at stage $4^{+}-5$ and placed into tissue culture will give rise to heart in the absence of either endoderm or ectoderm, that is, in the presumed absence of BMP signaling (Gonzalez-Sanchez and Bader 1990; Antin et al. 1994), suggest that only a transient exposure to BMP signals around stages 4-5 may be sufficient to induce cardiogenesis in competent tissues. Consistent with this interpretation, we have found that cardiogenesis is blocked by noggin administration to precardiac mesoendoderm when this tissue is explanted at stages 4-5 (Fig. 6), but when this tissue is explanted at stage 6, administration of noggin does not block subsequent cardiac myogenesis (data not shown). There is also evidence that

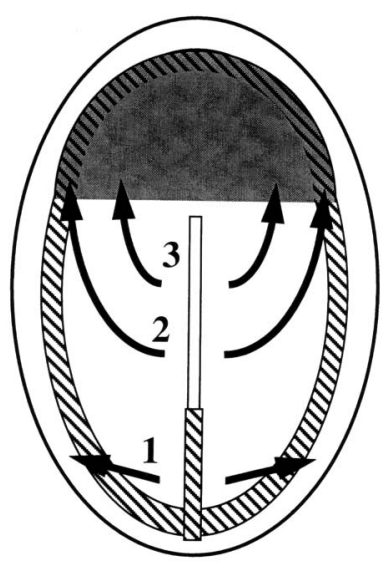

Figure 7. Model of avian cardiogenesis. At least two activities are required for cardiac myocyte induction. One activity is BMP signaling, which is present in the peripheral regions of the gastrula embryo and also in the posterior primitive streak; BMP-2 expression (hatched area) is outlined here, but BMP-4 and BMP-7 are expressed in similar domains and also have cardiacinducing properties. The other activity is a factor or factors present in the anterior endoderm, here designated factor $\mathrm{X}$ (shaded area). Cardiogenesis occurs where the two activities overlap, in the anterior lateral region. The numbered arrows indicate migration paths of mesodermal cells from the primitive streak. Normally only cells that follow path 2 encounter both inducing signals and hence undergo cardiogenesis. Cells that follow path 1 encounter only BMP signaling and form blood and extraembryonic membranes but will form heart if experimentally exposed to anterior endoderm (Schultheiss et al. 1995). Cells that follow path 3 encounter only factor X, and differentiate as paraxial head mesoderm (Rosenquist 1966), although they can form heart if exposed to BMP signaling (this paper).
TGF- $\beta$-class molecules are tightly adherent to the extracellular matrix (Reilly and Melton 1996), and thus BMPs may be present in the extracellular matrix attached to dissected precardiac mesoderm.

Although we favor the idea that BMP administration alters the fate of anterior medial mesoderm to become cardiac myocytes, it is a formal possibility that BMP treatment expands a pre-existing population of already specified cardiac myocytes within the anterior medial mesoderm that would otherwise undergo apoptosis in the absence of BMP signals.

\section{$B M P$ signaling is required for cardiac myogenesis}

We utilized the secreted protein noggin to determine whether BMP signaling is required for cardiogenesis. Noggin antagonizes BMP activity in a number of assays (Re'em-Kalma et al. 1995; Zimmerman et al. 1996). Recent work by Harland and colleagues has demonstrated that noggin interacts specifically with BMP-2 and BMP-4 and, to a lesser extent, with BMP-7 and not with other TGF- $\beta$ family members (Zimmerman et al. 1996). Furthermore, this same group demonstrated that noggin blocks interaction of BMP-4 with its cognate cell-surface receptor (Zimmerman et al. 1996). That noggin interferes with BMP signaling upstream of receptor activation is supported by the finding that noggin can block the activity of excess BMP ligand but not the activated form of the cognate receptor (Holley et al. 1996). In Drosophila, ectopic noggin has no effect in a $d p p$ mutant background, suggesting that the sole function of noggin in this biological context is to antagonize $d p p$ signaling. These findings, taken together with previous work demonstrating that the effects of noggin in Xenopus can be mimicked by agents that specifically block BMP-4 signals [i.e., dominant-negative BMP receptor reagents (Graff et al. 1994; Maeno et al. 1994; Suzuki et al. 1994; Hawley et al. 1995), antisense BMP-RNAs (Steinbeisser et al. 1995|], strongly suggest that the mechanism of noggin's biological effects is to sequester BMP ligands and thereby block the interaction of BMP ligands with their receptors. On the basis of these findings we have employed noggin in our own studies to probe the role of BMP family members in cardiac myocyte induction. We have found that administering noggin to cultured precardiac mesoendoderm inhibits differentiation of this tissue into heart, indicating that BMP signaling is required for cardiac differentiation.

Although the noggin experiments provide strong evidence that BMP signaling is required for differentiation of isolated precardiac mesoderm in vitro, it is more difficult to prove that BMP signaling is required for heart specification in vivo. Fifteen percent of mice that are homozygous null for BMP-2 show no evidence of heart formation, indicating a potential requirement for BMP-2 signaling in mouse heart specification (Zhang and Bradley 1996); in the remainder of the BMP-2 knockout mice, the heart forms but is abnormal. BMP-4 knockout mice typically die prior to gastrulation, and thus heart formation cannot be assessed in these embryos; however, oc- 
casionally such mice do live to later stages and in those cases heart tissue is produced (Winnier et al. 1995). BMP-7 homozygous null mice are born alive and show no heart defects (Dudley et al. 1995; Luo et al. 1995). Therefore, none of these BMP family members is absolutely required for cardiogenesis. These data are consistent with our findings that BMP-2 and BMP-4 are expressed in the endoderm and ectoderm, respectively, directly adjacent to the precardiac mesoderm and that BMP-2 and BMP-4 have indistinguishable cardiac-inducing properties. Therefore, it seems likely that heart formation in vivo can be at least partially supported by either BMP-2 or BMP-4 signals. Because of this functional redundancy, one would expect that some heart tissue would be present in mice genetically engineered to lack only one of these signaling molecules.

Although noggin can inhibit cardiac differentiation in vitro, it remains to be determined what role BMP antagonists play in cardiac specification in vivo. At stages 4-6, noggin RNA is expressed in Hensen's node and the forming notochord (R. Reshef and T.M. Schultheiss, unpubl.), but the extent to which noggin protein diffuses from its point of synthesis is unknown. Chordin, another BMP antagonist with similar biochemical properties to noggin (Piccolo et al. 1996), is known to be expressed in the notochord in Xenopus laevis (Sasai et al. 1994). It is possible that BMP antagonists diffusing from the node/notochord directly inhibit the cardiac-inducing activity of BMPs in the medial mesoderm. However, given the sharp concordance between the medial borders of BMP and CNkx-2.5 expression domains, it is also possible that BMP signaling directly induces the expression of CNkx-2.5 and other cardiac genes and that BMP antagonists function to restrict the domain of BMP expression. In such a model, BMP signaling would positively autoregulate the expression of $\mathrm{BMP}$ ligands, and the presence of BMP antagonists in the axial/medial regions of the embryo would act to inhibit expression of BMP ligands in this embryonic domain.

In summary, BMPs are expressed in a time and place that is consistent with their playing a role in heart specification; BMPs can induce ectopic cardiogenesis in competent regions of the embryo; and inhibition of BMP signaling blocks cardiac differentiation of the precardiac mesoderm. Taken together, these data imply that BMP signaling serves to specify which cells from within a cardiogenic field in the anterior embryo actually differentiate into heart.

\section{Signals that inhibit cardiac differentiation}

BMP-2-laden beads induced robust ectopic expression of CNkx-2.5 in anterior medial mesoderm in vivo, but induced only weak expression of GATA-4, and failed to induce $v M H C$ in this tissue. In contrast, when the anterior medial mesoendoderm was removed from the embryo and placed in tissue culture, administration of BMP-2 beads, or of soluble BMP-2 or BMP-4, induced full cardiac myogenesis, including robust expression of CNkx-2.5, GATA-4, vMHC, as well as beating. How- ever, if the anterior medial mesoendoderm was cultured in the presence of the adjacent neural plate and notochord, BMP-2 administration induced CNkx-2.5 strongly, GATA-4 weakly, and did not induce vMHC, the same profile of cardiac gene expression observed after placement of BMP-2 beads into the anterior medial region in vivo. This observation suggests that lack of a full cardiogenic response to BMP-2 beads in vivo can be attributed to inhibitory effects of the axial tissues on cardiogenesis. A repressive influence of neural tissues on vertebrate cardiac differentiation has been reported by others (Jacobson 1960; Jacobson and Duncan 1968; Climent et al. 1995).

Published reports (Antin et al. 1994) and our unpublished data have indicated that the ectoderm overlying the precardiac mesoderm inhibits terminal cardiac differentiation. Thus, inhibition of terminal cardiac differentiation may be a general property of gastrula/neurula ectoderm. The embryonic movements that occur during the period of cardiogenesis bring the developing heart away from the axial structures and ectoderm and toward the ventral side of the embryo. Such movements may serve to bring the cardiogenic tissues away from inhibitory influences and thus permit terminal cardiac differentiation to proceed.

\section{BMP family members activate the cardiac differentiation program to varying degrees}

In explant cultures, BMP-2 and BMP-4 induced complete cardiogenesis, whereas BMP-7 induced only CNkx-2.5 expression. Although the basis for the differential activity of these BMP family members is unknown, it is interesting to note that in humans, one activin-like serine/ threonine kinase receptor has high affinity for BMP-2, BMP-4, and BMP-7, and another receptor binds preferentially to BMP-2 and BMP-4 (Dijke et al. 1994). It is possible, therefore, that induction of $\mathrm{CNkx}-2.5$ expression is mediated by one set of BMP receptors (capable of interacting with BMP-2, BMP-4, and BMP-7), whereas other events (i.e., activation of GATA- 4 and $v M H C$ ) require activation of receptors specific for BMP-2/BMP-4. Alternatively, early and late events may both require the same BMP signals but at quantitatively different levels. In this scenario a single, common BMP signaling pathway could account for the observed results if it is activated to varying degrees by BMP-2/BMP-4 versus BMP-7 signals.

Whereas studies from other groups have suggested roles for activin and bFGF in heart formation, these molecules were not found to be active in the current studies. These differences are most likely attributable to differences in experimental design and point to roles for various signaling molecules at different stages of heart development. Activin has been found to induce heart formation when used at high doses in Xenopus animal caps (Logan and Mohun 1993). In those experiments, activin was added at early developmental time points, and the treated caps produced many other tissues besides heart. Thus, activin may participate in cardiac induction through its activity on early mesodermal patterning 
events. In the chick, activin and bFGF have been found to promote heart formation in the precardiac mesoderm cultured in serum-free medium (Sugi and Lough 1995). However, because these studies utilized tissues that were in the cardiac fate map, they support a possible role for activin and bFGF in the survival and differentiation of already committed cardiac mesoderm rather than in specification of the cardiac myocyte lineage. The current studies imply a specific role for BMPs in the induction of cardiac muscle from within a field of competent cells in the anterior mesoderm. Recently it has been reported that BMP-2, in combination with FGF-4, can induce cardiac differentiation in cultured stage 6 chick posterior lateral plate tissue, which does not normally form heart (Lough et al. 1996); this finding supports a role for BMP signaling in cardiac specification.

\section{Comparison of Drosophila and vertebrate cardiogenesis}

In Drosophila, the tinman gene is expressed in the heart and in certain other dorsal mesodermal structures and is required for cardiogenesis (Bodmer et al. 1990; Bodmer 1993). Initially, tinman is expressed throughout the mesoderm, under the control of the transcription factor twist (Bodmer et al. 1990; Azpiazu and Frasch 1993). Subsequently, tinman fades from most mesodermal cells but is maintained in dorsal cells that are in contact with dorsal ectoderm, which expresses the TGF- $\beta$ family member $d p p$ (Staehling-Hampton et al. 1994; Frasch 1995). In $d p p$ homozygous null flies, tinman expression is not maintained (Frasch 1995). If $d p p$ is misexpressed in more ventral regions, then the domain of tinman expression is expanded to include more ventral mesoderm (Frasch 1995). Thus, in Drosophila $d p p$ is required for maintenance of tinman expression, and ectopic $d p p$ can expand the domain of tinman expression into ventral mesoderm.

In the chick and other vertebrates, Nkx-2.5, a tinman homolog, is expressed in the developing heart (Komuro and Izumo 1993; Lints et al. 1993; Tonissen et al. 1994; Schultheiss et al. 1995). In the current work, we have found that the $d p p$ homologs BMP-2 and BMP-4 can induce CNkx-2.5 expression within a competent domain of the embryo. Thus in both chick and Drosophila, BMPlike signaling regulates tinman family gene expression. The details of Nkx-2.5 regulation are somewhat different, however, because in the chick there appears to be no initial BMP-independent phase of $\mathrm{Nkx}-2.5$ expression (Schultheiss et al. 1995). Another parallel is that in both Drosophila and chick, $d p p / B M P$ signaling is apparently required for tinman/Nkx-2.5 expression. Thus, fundamental components of the regulation of the cardiac differentiation program are conserved between Drosophila and chick. The localization of BMP-2 to tissues adjacent to the heart-forming region in amphibians (Clement et al. 1995) and in the mouse (Lyons et al. 1995) suggests that the cardiogenic role of BMPs may be conserved in other vertebrates.

One further parallel between the regulation of Dro- sophila and vertebrate cardiogenesis is that in both species ectopic $d p p / B M P$ signaling can induce ectopic tinman/Nkx-2.5 expression but cannot induce full ectopic cardiogenesis in vivo. As discussed above, in the chick this lack of a complete cardiogenic response to BMP signaling can be attributed to inhibitory signals emitted by the neural plate and/or notochord that block cardiogenesis downstream of Nkx-2.5 expression. It will be of interest to determine whether analogous inhibitory influences from, for example, neurogenic ectoderm, function similarly to block terminal cardiac differentiation in Drosophila.

\section{General considerations}

Current views of vertebrate mesoderm patterning, derived largely from studies in amphibians, suggest a dorsoventral framework for mesodermal cell type determination (Sive 1993; Fainsod et al. 1994; Graff et al. 1994; Kessler and Melton 1994; Schmidt et al. 1995; DeRobertis and Sasai 1996). In this view, notochord is the most dorsal cell type, skeletal muscle more lateral, and blood most ventral. Heart is often considered a dorsal cell type, because it is derived from dorsal blastomeres (Dale and Slack 1987), is expanded under certain dorsalizing treatments such as lithium (Drysdale et al. 1994), can be induced by high doses of the mesoderm inducer activin (Logan and Mohun 1993), and requires organizer activity for induction (Sater and Jacobson 1989; Nascone and Mercola 1995). Here, however, we show that BMP-2/ BMP-4, which are ventralizing agents in this mesoderm patterning scheme, play a role in cardiac cell type determination, and that noggin, a dorsalizing agent, can act to inhibit cardiac myocyte formation. Rather than attempting to fit the heart into a simple dorsoventral framework, it seems more realistic to consider heart specification as a two step process: First, cells are anteriorized by factors in the organizer and/or anterior endoderm. Exposure of these cells to BMP-2/BMP-4 then results in the formation of heart, an anterior ventral tissue. Although lithium treatment of Xenopus embryos results in hyperdorsalized embryos that exhibit a profound reduction of ventral BMP-4 expression during gastrulation (Fainsod et al. 1994), we suggest that heart formation in such embryos may rely on the subsequent expression of BMP family members in either the organizer itself (Moos et al. 1995) or in the pharyngeal endoderm (Clement et al. 1995; Hemmati-Brenvanlou and Thomsen 1995) that subsequently lies adjacent to the precardiac region. Similar, multistage determination pathways are likely to act in the differentiation of other mesodermal cell types.

\section{Materials and methods}

Cloning of TGF- $\beta$ family members by degenerate PCR

Degenerate PCR primers $5^{\prime}$-CTCTGG(AGC)(AG)IGA(CT)TGG(AG)T(AGC)(AG)T(ACT)GC(ACT)CC and $5^{\prime}$-A/GAT)|CT)T(GCT)I/GA)/CT)IGGI/GA/C(AG)CA(AC)CA were designed to amplify -180 bases of genes encoding a subset of TGF- $\beta$ family members that includes the BMPs, Vg-1, and nodal. PCR was 
performed on cDNA generated from stage 5 anterior endoderm as described previously (Schultheiss et al. 1995). PCR products were subcloned into Bluescript II KS+ and sequenced using dideoxy methods. Of 36 clones, 5 corresponded to BMP-2, 8 were BMP-5, and 7 were BMP-7. The others were not related to the TGF- $\beta$ family.

\section{In situ hybridization}

Whole-mount in situ hybridization was performed as described previously (Schultheiss et al. 1995) using probes to chick BMP-2 (Laufer et al. 1994), BMP-4 (Liem et al. 1995), BMP-7 (Oh et al. 1996), CNkx-2.5 (Schultheiss et al. 1995), and GATA-4 (Laver-

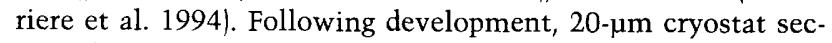
tions (Microm) were cut on gelatin-embedded embryos, as described previously (Schultheiss et al. 1995).

\section{New cultures}

Heparin-acrylamide beads (Sigma) were soaked in $25 \mu$ l of a $5-\mathrm{ng} / \mu \mathrm{l}$ solution of human recombinant BMP-2 (a generous gift from Genetics Institute) on ice for $1 \mathrm{hr}$. BMP- 2 beads or control beads soaked in carrier protein $(0.1 \% \mathrm{BSA})$ were placed in stage 3 to 5 embryos which had been placed in New culture (New 1955). Embryos were incubated until stage 8-11, photographed, fixed in $4 \%$ paraformaldehyde, and processed for whole-mount in situ hyridization.

\section{Explant cultures}

Tissues were dissected from chick embryos (Spafas) with tungsten needles and cultured in type I collagen gels (Munsterberg et al. 1995) in chick embryo medium (CEM): DMEM- $\alpha$ (GIBCO), with $10 \%$ fetal bovine serum (FBS), $5 \%$ chick embryo extract (CEX), 1\% Pen-Strep, and 1\% L-glutamine. All of the following supplements were added to both the media and to the collagen gels. Human recombinant BMP-2, BMP-4, and BMP-7 was obtained from Genetics Institute. Supernatant from COS cells expressing human recombinant activin $\beta A$ was kindly provided by Karen Symes (Boston University, MA). Activin was used at a range of concentrations from 2 to $100 \mathrm{U} / \mathrm{ml}(-0.2-10 \mathrm{ng} / \mathrm{ml})$ with essentially identical results; this range of concentrations induces a variety of mesodermal cell types from Xenopus animal caps (Smith et al. 1988). Recombinant human bFGF was purchased from Promega. noggin-conditioned medium and noggin control medium were harvested from $\mathrm{CHO}$ cells stably expressing Xenopus noggin (Smith and Harland 1992) or $\mathrm{CHO}$ cells alone; the CHO lines were kindly provided by R. Harland (University of California, Berkeley). Noggin or control conditioned media were each mixed in a 1:1 ratio with CEM, and supplemented with FBS and CEX to bring the total concentration of these constituents up to $10 \%$ and $5 \%$, respectively.

\section{$R T-P C R$}

Preparation of cDNA and analysis by PCR (incorporating trace amounts of $\left[\alpha-{ }^{32} \mathrm{P}\right]$ for the genes GAPDH, CNkx-2.5, and vMHC are essentially as described previously (Schultheiss et al. 1995). For GATA-4, PCR primers 5'-CTCCTACTCCACCCCTTACC and $5^{\prime}$-GCCCTGTGCCATCTCTCCTC were used, PCR was performed for $30 \mathrm{cycles}$ at $52^{\circ} \mathrm{C}$ annealing temperature with $5 \%$ formamide, and otherwise as described (Schultheiss et al. 1995). Samples were loaded onto $6 \%$ acrylamide gels and exposed to radiographic film (Fuji).

\section{Acknowledgments}

We thank Maureen O'Brien, Steve Xydas, and Tak Chun for technical assistance; Randy Johnson, Tom Jessell, and Katherine Yutzey for providing probes for in situ hybridization; Mike Levin for instruction in the New culture technique; Genetics Institute for providing recombinant BMP-2, BMP-4, and BMP-7; Karen Symes for providing activin-containing COS cell supernatant; Richard Harland for providing $\mathrm{CHO}$ cells expressing Xenopus noggin; and Martha Marvin, Charlie Murtaugh, Ben Novitch, Rami Reshef, and Doug Spicer for providing valuable comments on the manuscript. This work was supported by a grant to A.B.L. from The Council for Tobacco Research U.S.A. This work was done during the tenure of an established investigatorship from the American Heart Association to A.B.L. T.M.S. is a Howard Hughes Medical Institute Physician Postdoctoral Fellow.

The publication costs of this article were defrayed in part by payment of page charges. This article must therefore be hereby marked "advertisement" in accordance with 18 USC section 1734 solely to indicate this fact.

\section{References}

Antin, P.B., R.G. Taylor, and T. Yatskievych. 1994. Precardiac mesoderm is specified during gastrulation in quail. Dev. Dynam. 200: 144-154.

Arceci, R.J., A.A.J. King, C. Simon, S.H. Orkin, and D.B. Wilson. 1993. Mouse GATA-4: A retinoic acid-inducible GATAbinding transcription factor expressed in endodermally derived tissues and heart. Mol. Cell. Biol. 13: 2235-2246.

Azpiazu, N. and M. Frasch. 1993. tinman and bagpipe: Two homeo box genes that determine cell fates in the dorsal mesoderm of Drosophila. Genes \& Dev. 7: 1325-1340.

Bate, M. 1993. The mesoderm and its derivatives. In The deve1opment of Drosophila melanogaster (ed. M. Bate and A.M. Arias), pp. 1013-1090. Cold Spring Harbor Laboratory Press, NY.

Bisaha, J.G. and D. Bader. 1991. Identification and characterization of a ventricular-specific avian myosin heavy chain, VMHC1: Expression in differentiating cardiac and skeletal muscle. Dev. Biol. 148: 355-364.

Bodmer, R. 1993. The gene tinman, is required for specification of the heart and visceral muscles in Drosophila. Development 118: 719-729.

Bodmer, R., L.Y. Jan, and Y.N. Jan. 1990. A new homeoboxcontaining gene, $m s h-2$, is transiently expressed early during mesoderm formation in Drosophila. Development 110: 661669.

Clement, J.H., P. Fettes, S. Knochel, J. Lef, and W. Knochel. 1995. Bone morphogenetic protein 2 in the early development of Xenopus laevis. Mech. Dev. 52: 357-370.

Climent, S., M. Sarasa, I.M. Villar, and N.L. Murillo-Ferrol. 1995. Neurogenic cells inhibit the differentiation of cardiogenic cells. Dev. Biol. 171: 130-148.

Dale, L. and J.M. Slack. 1987. Fate map for the 32-cell stage of Xenopus laevis. Development 99: 527-551.

DeRobertis, E.M. and Y. Sasai. 1996. A common plan for dorsoventral patterning in bilateralia. Nature 380: 37-40.

Dijke, P.t., H. Yamashita, T.K. Sampath, A.H. Reddi, M. Estevez, D.L. Riddle, H. Ichijo, C.H. Heldin, and K. Miyazono. 1994. Identification of type I receptors for osteogenic protein-1 and bone morphogenetic protein-4. J. Biol. Chem. 269: 16985-16988.

Drysdale, T.A., K.F. Tonissen, K.D. Patterson, M.J. Crawford, and P.A. Krieg. 1994. Cardiac troponin I is a heart-specific 
marker in the Xenopus embryo: Expression during abnormal heart morphogenesis. Dev. Biol. 165: 432-441.

Dudley, A.T., K.M. Lyons, and E.J. Robertson. 1995. A requirement for bone morphogenetic protein-7 during development of the mammalian kidney and eye. Genes \& Dev. 9: 27952807.

Fainsod, A., H. Steinbeisser, and E.M. De Robertis. 1994. On the function of BMP-4 in patterning the marginal zone of the Xenopus embryo. EMBO I. 13: 5015-5025.

Frasch, M. 1995. Induction of visceral and cardiac mesoderm by ectodermal Dpp in the early Drosophila embryo. Nature 374: 464-467.

Garcia-Martinez, V. and G.C. Schoenwolf. 1993. Primitive streak origin of the cardiovascular system in avian embryos. Dev. Biol. 159: 706-719.

Gonzalez-Sanchez, A. and D. Bader. 1990. In vitro analysis of cardiac progenitor cell differentiation. Dev. Biol. 139: 197209.

Graff, J.M., R.S. Thies, J.J. Song, A.J. Celeste, and D.A. Melton. 1994. Studies with a Xenopus BMP receptor suggest that ventral mesoderm-inducing signals override dorsal signals in vivo. Cell 79: 169-179.

Grepin, C., L. Dagnino, L. Robitaille, L. Haberstroh, T. Antakly, and M. Nemer. 1994. A hormone-encoding gene identifies a pathway for cardiac but not skeletal muscle gene transcription. Mol. Cell. Biol. 14: 3115-3129.

Hamburger, V. and H.L. Hamilton. 1951. A series of normal stages in the development of the chick embryo. J. Morphol. 88: 49-92.

Han, Y., J.E. Dennis, L. Cohen-Gould, D.M. Bader, and D.A. Fischman. 1992. Expression of sarcomeric myosin in the presumptive myocardium of chicken embryos occurs within six hours of myocyte commitment. Dev. Dynam. 193: 257-265.

Hawley, S.H., K. Wunnenberg-Stapleton, C. Hashimoto, M.N. Laurent, T. Watabe, B.W. Blumberg, and K.W. Cho. 1995. Disruption of BMP signals in embryonic Xenopus ectoderm leads to direct neural induction. Genes \& Dev. 9: 2923-2935.

Hemmati-Brivanlou, A. and G.H. Thomsen. 1995. Ventral mesodermal patterning in Xenopus embryos: Expression patterns and activities of BMP-2 and BMP-4. Dev. Genet. 17: 78-89.

Hogan, B.L.M. 1996. Bone morphogenetic proteins in development. Curr. Opin. Genet. Dev. 6: 432-438.

Holley, S.A., J.L. Neul, L. Attisano, J.L. Wrana, Y. Sasai, M.B. O'Connor, E.M. DeRobertis, and E.L. Ferguson. 1996. The Xenopus dorsalizing factor noggin ventralizes Drosophila embryos by preventing dpp from activating its receptor. Cell 86: 607-617.

Holtzer, H., T. Schultheiss, C. Dilullo, J. Choi, M. Costa, M. Lu, and S. Holtzer. 1990. Autonomous expression of the differentiation programs of cells in the cardiac and skeletal myogenic lineages. Ann. N.Y. Acad. Sci. 599: 158-169.

Ip, H.S., D.B. Wilson, M. Heikinheimo, Z. Tang, C.N. Ting, M.C. Simon, J.M. Leiden, and M.S. Parmacek. 1994. The GATA-4 transcription factor transactivates the cardiac muscle-specific troponin $C$ promoter-enhancer in nonmuscle cells. Mol. Cell. Biol. 14: 7517-7526.

Jacobson, A.G. 1960. Influences of ectoderm and endoderm on heart differentiation in the newt. Dev. Biol. 2: 138-154.

Jacobson, A.G., and J.T. Duncan. 1968. Heart induction in salamanders. J. Exp. Zool. 167: 79-103.

Jacobson, A.G. and A.K. Sater. 1988. Features of embryonic induction. Development 104: 341-359.

Kessler, D.S. and D.A. Melton. 1994. Vertebrate embryonic induction: Mesodermal and neural patterning. (Review). Science 266: 596-604.
Kingsley, D. 1994. The TGF- $\beta$ superfamily: New members, new receptors, and new genetic tests of function in different organisms. Genes \& Dev. 8: 133-146.

Komuro, I. and S. Izumo. 1993. Csx: A murine homeobox-containing gene specifically expressed in the developing heart. Proc. Nat1. Acad. Sci. 90: 8145-8149.

Laufer, E., C.E. Nelson, R.L. Johnson, B.A. Morgan, and C. Tabin. 1994. Sonic hedgehog and Fgf-4 act through a signalling cascade and feedback loop to integrate growth and patterning of the developing limb bud. Cell 79: 993-1003.

Laverriere, A.C., C. MacNeill, C. Mueller, R.E. Poelmann, J.B.E. Burch, and T. Evans. 1994. GATA-4/5/6, a subfamily of three transcription factors transcribed in developing heart and gut. J. Biol. Chem. 269: 23177-23184.

Lee, K.-H., Q. Xu, and R.E. Breitbart. 1996. A new tinman-related gene, $\mathrm{nkx}-2.7$, anticipates the expression of $\mathrm{nkx}-2.5$ and nkx-2.3 in zebrafish heart and pharyngeal endoderm. Dev. Biol. 180: 722-731.

Liem, K.F., G. Tremml, H. Roelink, and T.M. Jessell. 1995. Dorsal differentiation of neural plate cells induced by BMP-mediated signals from epidermal ectoderm. Cell 82: 969-979.

Lints, T.J., L.M. Parsons, L. Hartley, I. Lyons, and R.P. Harvey. 1993. Nkx-2.5: A novel murine homeobox gene expressed in early heart progenitor cells and their myogenic descendants. Development 119: 419-431.

Logan, M. and T. Mohun. 1993. Induction of cardiac muscle differentiation in isolated animal pole explants of Xenopus laevis embryos. Development 118: 865-875.

Lough, J., M. Barron, M. Brogley, Y. Sugi, D.L. Bolender, and X.L. Zhu. 1996. Combined BMP-2 and FGF-4, but neither factor alone, induces cardiogenesis in non-precardiac embryonic mesoderm. Dev. Biol. 178: 198-202.

Luo, G., C. Hoffman, A.L. Bronckers, M. Sohocki, A. Bradley, and G. Karsenty. 1995. BMP-7 is an inducer of nephrogenesis, and is also required for eye development and skeletal patterning. Genes \& Dev. 9: 2808-2820.

Lyons, K.M., B.L. Hogan, and E.J. Robertson. 1995. Colocalization of BMP 7 and BMP 2 RNAs suggests that these factors cooperatively mediate tissue interactions during murine development. Mech. Dev. 50: 71-83.

Maeno, M., R.C. Ong, A. Suzuki, N. Ueno, and H.F. Kung. 1994. A truncated bone morphogenetic protein 4 receptor alters the fate of ventral mesoderm to dorsal mesoderm: Roles of animal pole tissue in the development of ventral mesoderm (see comments). Proc. Natl. Acad. Sci. 91: 10260-10264.

Massague, J., L. Attisano, and J.L. Wrana. 1994. The TGF- $\beta$ family and its composite receptors. Trends Cell Biol. 4: 172-178.

Molkentin, J.D., D.V. Kalvakolanu, and B.E. Markham. 1994. Transcription factor GATA-4 regulates cardiac muscle-specific expression of the $\alpha$-myosin heavy-chain gene. Mol. Cell. Biol. 14: 4947-4957.

Moos, M., S. Wang, and M. Krinks. 1995. Anti-dorsalizing morphogenetic protein is a novel TGF- $\beta$ homolog expressed in the Spemann organizer. Development 121: 4293-4301.

Munsterberg, A.E., J. Kitajewski, D.A. Bumcrot, A.P. McMahon, and A.B. Lassar. 1995. Combinatorial signaling by sonic hedgehog and Wnt family members induces myogenic bHLH gene expression in the somite. Genes \& Dev. 9: 2911-2922.

Nascone, N. and M. Mercola. 1995. An inductive role for the endoderm in Xenopus cardiogenesis. Development 121: 515-523.

New, D.A.T. 1955. A new technique for the culture of the chick embryo in vitro. J. Embryol. Exp. Morphol. 3: 326-331.

Oh, S.H., R. Johnson, and D.K. Wu. 1996. Differential expression of bone morphogenetic proteins in the developing vestibular and auditory sensory organs. J. Neurosci. 16: 6463-6475. 
Piccolo, S., Y. Sasai. B. Lu, and E.M. DeRobertis. 1996. Dorsoventral patterning in Xenopus: Inhibition of ventral signals by direct binding of chordin to BMP-4. Cell 86: 589-598.

Re'em-Kalma, Y., T. Lamb, and D. Frank. 1995. Competition between noggin and bone morphogenetic protein 4 activities may regulate dorsalization during Xenopus development. Proc. Nat1. Acad. Sci. 92: 12141-12145.

Reilly, K.M. and D.A. Melton. 1996. Short-range signaling by candidate morphogenes of the TGF- $\beta$ family and evidence for a relay mechanism of induction. Cell 86: 743-754.

Rosenquist, G.C. 1966. A radioautographic study of labelled grafts in the chick blastoderm. Carnegie Inst. Wash. Contrib. Embryol. 38: 71-110.

Rosenquist, G.C. and R.L. DeHaan. 1966. Migration of precardiac cells in the chick embryo: A radioautographic study. Carnegie Inst. Wash. Contrib. Embryol. 38: 111-121.

Sasai, Y., B. Lu, H. Steinbeisser, D. Geissert, L.K. Gont, and E.M. DeRobertis. 1994. Xenopus chordin: A novel dorsalizing factor activated by organizer-specific homeobox genes. Cell 79: 779-790.

Sater, A.K. and A.G. Jacobson. 1989. The specification of heart mesoderm occurs during gastrulation in Xenopus laevis. Development 105: 821-830.

- 1990. The restriction of the heart morphogenetic field in Xenopus laevis. Dev. Biol. 140: 328-336.

Schmidt, J., V. Francois, E. Bier, and D. Kimelman. 1995. Drosophila short gastrulation induces an ectopic axis in Xenopus: Evidence for conserved mechanisms of dorso-ventral patterning. Development 121: 4319-4328.

Schultheiss, T.M., S. Xydas, and A.B. Lassar. 1995. Induction of avian cardiac myogenesis by anterior endoderm. Development 121: 4203-4214.

Sive, H.L. 1993. The frog princess: A molecular formula for dorsoventral patterning in Xenopus. Genes \& Dev. 7: 1-12.

Smith, J.C., M. Yaqoob, and K. Symes. 1988. Purification, partial characterization, and biological effects of the XTC mesoderm-inducing factor. Development 103: 591-600.

Smith, W.C. and R.M. Harland. 1992. Expression cloning of noggin, a new dorsalizing factor localized to the Spemann organizer in Xenopus embryos. Cell 70: 829-840.

Smith, W.C., A.K. Knecht, M. Wu, and R.M. Harland. 1993. Secreted noggin protein mimics the Spemann organizer in dorsalizing Xenopus mesoderm. Nature 361: 547-549.

Staehling-Hampton, K., F.M. Hoffmann, M.K. Baylies, E. Rushton, and M. Bate. 1994. dpp induces mesodermal gene expression in Drosophila. Nature 372: 783-786.

Steinbeisser, H., A. Fainsod, C. Niehrs, Y. Sasai, and E.M.D. Robertis. 1995. The role of gsc and BMP-4 in dorsal-ventral patterning of the marginal zone in Xenopus: A loss-of-function study using antisense RNA. EMBO T. 14: 5230-5243.

Sugi, Y. and J. Lough. 1995. Activin-A and FGF-2 mimic the inductive effects of anterior endoderm on terminal cardiac myogenesis in vitro. Dev. Biol. 168: 567-574.

Suzuki, A., R.S. Thies, N. Yamaji, J.J. Song, J.M. Wozney, K. Murakami, and N. Ueno. 1994. A truncated bone morphogenetic protein receptor affects dorsal-ventral patterning in the early Xenopus embryo (see comments). Proc. Natl. Acad. Sci. 91: 10255-10259.

Tonissen, K.F., T.A. Drysdale, T.J. Lints, R.P. Harvey, and P.A. Krieg. 1994. $X N k x-2.5$, a Xenopus gene related to $N k x-2.5$ and tinman: Evidence for a conserved role in cardiac development. Dev. Biol. 162: 325-328.

Wall, N.A. and B.M. Hogan. 1994. The TGF- $\beta$ related genes in development. Curr. Opin. Genet. Dev. 4: 517-522.

Winnier, G., M. Blessing, P.A. Labosky, and B.L. Hogan. 1995. Bone morphogenetic protein- 4 is required for mesoderm for- mation and patterning in the mouse. Genes \& Dev. 9: 2105 2116.

Zhang, H. and A. Bradley. 1996. Mice deficient for BMP2 are nonviable and have defects in amnion/chorion and cardiac development. Development 122: 2977-2986.

Zimmerman, L.B., J.D. Jésus-Escobar, and R.M. Harland. 1996. The Spemann organizer signal noggin binds and inactivates bone morphogenetic protein-4. Cell 86: 599-606. 


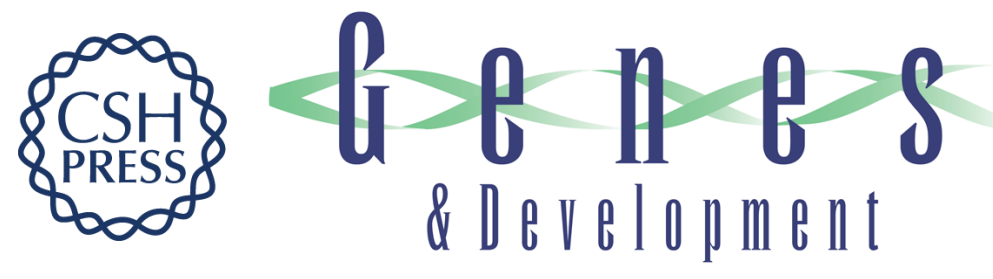

\section{A role for bone morphogenetic proteins in the induction of cardiac myogenesis.}

T M Schultheiss, J B Burch and A B Lassar

Genes Dev. 1997, 11:

Access the most recent version at doi:10.1101/gad.11.4.451

References This article cites 73 articles, 32 of which can be accessed free at: http://genesdev.cshlp.org/content/11/4/451.full.html\#ref-list-1

License

Email Alerting

Service

Receive free email alerts when new articles cite this article - sign up in the box at the top right corner of the article or click here.

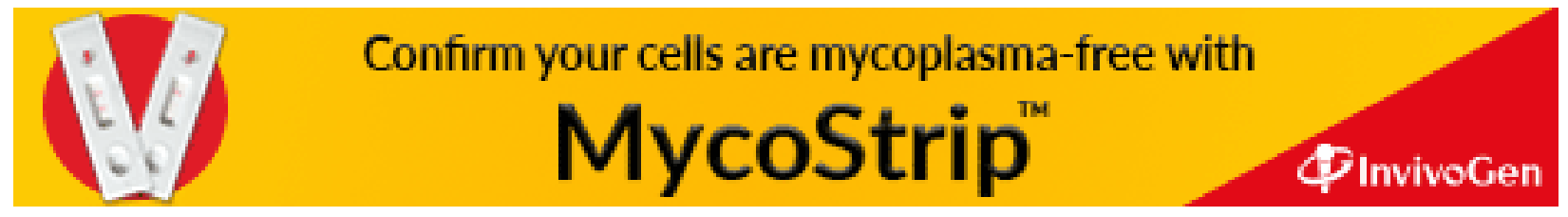

